\title{
Acute pancreatitis and serological evidence of infection with Mycoplasma pneumoniae
}

\author{
R. FREEMAN AND M. J. MCMAHON, \\ From the Virology Department, Regional Public Health Laboratory, Leeds, and the University Department \\ of Surgery, The General Infirmary, Leeds
}

SUMMARY Paired acute and convalescent serum samples from 27 consecutive patients with acute pancreatitis were examined for evidence of infection with several viral agents. Evidence of infection with Coxsackie viruses group B was found in three patients, and of infection with Mycoplasma pneumoniae in nine patients $(33 \%)$. This latter finding confirms recent reports from Scandinavia linking pancreatitis and serological evidence of infection with Mycoplasma pneumoniae. The possibility that a true association exists between the two conditions is considered, together with alternative explanations, and further work is envisaged to elucidate these findings.

Most cases of acute pancreatitis are associated with biliary tract disease, over-indulgence in alcohol, or metabolic diseases (Edlund, 1970), but a proportion of patients have no such association, and even in those with such alleged predispositions the link with acute pancreatitis is incompletely understood.

It has long been known that mumps virus infection may be accompanied by a mild pancreatitis, and Coxsackie viruses of group B have been associated with the disease (Ursing, 1973). Two recent reports from Scandinavia (Leinikki et al., 1973; Mårdh and Ursing, 1974) have shown an association between acute pancreatitis and serological evidence of infection with Mycoplasma pneumoniae.

In the present study paired serum samples from cases of acute pancreatitis were examined for evidence of infection with the above and several other infective agents.

\section{Methods}

PATIENTS

The study was carried out on 27 consecutive patients with acute pancreatitis admitted to the General Infirmary at Leeds during 1976 and 1977. The diagnosis was based upon a consistent clinical impression coupled with a serum amylase level greater than 1000 Somogyi units/dl. An associated condition has so far been identified in 17 patients (Table).

Received for publication 10 January 1978
Acute serum samples were taken at, or near, admission and at least one further sample was obtained, usually after seven to 10 days, although in several cases the interval was longer. No samples were taken for attempted isolation of viruses or Mycoplasma pneumoniae.

Convalescent (second) serum samples were screened at a dilution of 1 in 32 for the presence of complement-fixing antibody to the following agents: Mycoplasma pneumoniae, Coxiella burneti (phase 2), influenza viruses types $A$ and $B$, adenovirus, chlamydia subgroup $B$, and mumps virus. A standard method of testing was employed (Bradstreet and Taylor, 1962), adapted for use in micro-titre trays. Detection of antibody in the convalescent sample at the screening dilution resulted in the testing in parallel of both the acute and convalescent samples at dilutions of serum ranging from 1 in 8 to 1 in 512. A fourfold, or greater, rise in antibody level between the two samples was taken as serological evidence of infection with the relevant agent. In all such instances the result was repeated on at least two separate occasions before being accepted as being reproducible.

Antibody to mumps virus was also measured by the haemagglutination inhibition test.

Each pair of serum samples was also tested for the presence of neutralising antibodies to Coxsackie viruses group B, types 1-6, using a standard technique employing LLC $\mathrm{MK}_{2}$ cells and a virus inoculum of 32-320 tissue culture infecting doses (TCID 50 ). In these tests sera were tested in parallel at serum dilutions ranging from 1 in 16 to 1 in 4096. 
Table Brief details of patient studied and results of mycoplasma and Coxsackie virus serology

\begin{tabular}{|c|c|c|c|c|c|}
\hline Patient & $\operatorname{Age}(y)$ & $\operatorname{Sex}$ & Associated condition & $\begin{array}{l}\text { Mycoplasma pneumoniae } \\
\text { serology }\end{array}$ & Features of subgroup \\
\hline 1 & 65 & $\mathbf{M}$ & None known & $\mathbf{P}$ & \\
\hline 2 & 69 & $\mathbf{F}$ & Gallstones & $\mathbf{P}$ & Significant rise in antibody to $M$. pneumoniae \\
\hline 3 & 58 & $\mathbf{F}$ & Gallstones & $\mathbf{P}$ & \\
\hline 4 & 70 & $\mathbf{F}$ & Stricture of CBD & $\mathbf{P}$ & Age: mean $64 \cdot 2 \mathrm{yr}$ \\
\hline 5 & 68 & $\mathbf{F}$ & None known & $\mathbf{P}$ & Range: $43-72$ yr \\
\hline 6 & 72 & $\mathbf{F}$ & Stone in CBD & $\mathbf{P}$ & Male: female ratio $1: 8$ \\
\hline 7 & 64 & $\mathbf{F}$ & None known & $\mathbf{P}$ & \\
\hline 8 & 69 & $\mathbf{F}$ & Gallstones & $\mathbf{P}$ & Associated condition in 6 patients $(66 \%)$ \\
\hline 9 & 43 & $\mathbf{F}$ & Alcohol & $\mathbf{P}$ & \\
\hline 10 & 67 & $\mathbf{F}$ & None known & $\mathbf{N}$ & \\
\hline 11 & 72 & $\mathbf{M}$ & None known & $\mathbf{N}$ & \\
\hline 12 & 70 & $\mathbf{F}$ & Gallstones & $\mathbf{N}$ & No rise in antibody to $M$. pneumoniae \\
\hline 13 & 74 & $\mathbf{F}$ & Chronic pancreatic damage & $\mathbf{N}$ & \\
\hline 14 & 76 & $\mathbf{F}$ & Gallstones & $\mathbf{N}$ & Age: mean $62.9 \mathrm{yr}$ \\
\hline 15 & 56 & $\mathbf{M}$ & None known & $\mathbf{N}$ & \\
\hline 16 & 73 & $\mathbf{F}$ & Gallstones & $\mathbf{N}$ & Range: $23-85$ yr \\
\hline 17 & 34 & $\mathbf{M}$ & Alcohol & $\mathbf{N}$ & \\
\hline 18 & 85 & $\mathbf{M}$ & Gallstones & $\mathrm{N}^{*}$ & Male:Female ratio $7: 11$ \\
\hline 19 & 68 & $F$ & Gallstones & $\mathbf{N}$ & \\
\hline 20 & 53 & $\mathbf{M}$ & None known & $\mathbf{N}$ & \\
\hline 21 & 69 & $\mathbf{F}$ & None known & $\mathbf{N}$ & Associated condition in 11 patients $(61 \cdot 6 \%)$ \\
\hline 22 & 78 & $\mathbf{F}$ & None known & $\mathbf{N}^{*}$ & \\
\hline 23 & 23 & $\mathbf{F}$ & Gallstones & $\mathbf{N}$ & \\
\hline 24 & 73 & $\mathbf{F}$ & Gallstones & $\mathbf{N}$ & \\
\hline 25 & 34 & $\mathbf{M}$ & None known & $\mathrm{N}^{*}$ & \\
\hline 26 & 52 & $\mathbf{F}$ & Gallstones & $\mathbf{N}$ & \\
\hline 27 & 66 & $\mathbf{M}$ & Gallstones & $\mathbf{N}$ & \\
\hline
\end{tabular}

CBD: common bile duct. $\mathrm{P}$ : positive. $\mathrm{N}$ : negative.

*These three patients had serological evidence of infection with Coxsackie virus group B

In those instances in which significant rises in antibody to Mycoplasma pneumoniae were found, aliquots of the sera were sent to a second testing laboratory for independent verification of the results.

\section{Results}

Brief details of each patient are found in the Table, together with results of tests for antibodies to Mycoplasma pneumoniae and Coxsackie viruses group B. No serological evidence of infection with Coxiella burneti, influenza viruses types A or B, adenovirus, or chlamydia subgroup B was found, and wherever antibodies to mumps virus were detected, whether by complement-fixation or haemagglutination inhibition, no significant differences in titre between the acute and convalescent serum samples were found.

\section{Discussion}

The Table shows that serological evidence of infection with Coxsackie viruses group B was found in three out of 27 patients $(11.1 \%)$. Of these three patients, two were found to have evidence of infection with Coxsackie virus group B type 2, the third patient with type 3 . The association of such infections with acute pancreatitis has been well documented (Ursing, 1973).

However, the results also show that evidence of infection with Mycoplasma pneumoniae was obtained in nine out of 27 patients (33\%). This incidence is of the same order as that reported by Leinikki et al. (1973), in whose series 18 out of 56 cases were found to show such evidence. Our results thus provide an independent confirmation, in a different setting, of that report. It is important to note that no evidence of infection with $M y c o$ plasma pneumoniae was found in any of the three patients with evidence of Coxsackie virus infection. Verification of the antibody rises to Mycoplasma pneumoniae by both internal reproducibility (our testing), and by an independent laboratory, would appear to make certain that these patients show a significant rise in complement-fixing antibody over the course of their illness. We have recently examined several sera taken many weeks after the onset of the illness, and in those patients in whom serological evidence of infection was already present we found that the antibody had persisted and, in all cases, risen further in titre.

Four of the nine patients who were found to have serological evidence of infection with Mycoplasma pneumoniae were also shown to have gallstones. Although the association between gallstones and 
pancreatitis has long been recognised, there is still doubt about the mechanism by which they produce an attack of pancreatitis, although recent evidence suggests that pancreatitis may result from the passage of a small stone through the bile duct and ampulla (Acosta and Ledesma, 1974; Kelly, 1976). Injection of bile into the pancreatic duct has been found to be a reliable way to induce pancreatitis in experimental animals, but attacks of greater severity have been produced by the injection of increasing doses of staphylococcal exotoxin (Thal and Molestina, 1955). It is possible that Mycoplasma pneumoniae, an organism with an affinity for cholesterol (Hayflick, 1967), may potentiate the effect of gallstones in the production of pancreatitis in man.

It is also interesting to note that one of the three patients with evidence of infection with Coxsackie viruses group B was also found to have gallstones (Table).

Four additional questions are raised by these findings.

Firstly, it is logical to ask if the complementfixing antibody detected here is specific to the organism. The lack of any rise in antibodies to a wide range of viral antigens makes a generalised non-specific production of antibody unlikely, and the lack of a rise in antibody to Mycoplasma pneumoniae in those three patients showing a rise in antibody to the Coxsackie viruses also argues against this possibility. An obvious way to clarify this point further would be the testing of those sera containing antibody to Mycoplasma pneumoniae for the presence of other antibodies commonly associated with this organism, for instance cold agglutinin antibodies, Streptococcus 'MG' antibodies, and metabolic-inhibiting antibodies (Cruickshank et al., 1973).

Secondly, it is clear that attempts should be made to isolate Mycoplasma pneumoniae from patients with acute pancreatitis, although it must be emphasised that cultivation of the organism from the nasopharynx would still not provide conclusive evidence of a causal association with acute pancreatitis. Isolation of the organism from the exudate of the inflamed pancreas would, however, be of great importance.

Thirdly, attempts might be made to link Mycoplasma pneumoniae infection and acute pancreatitis in other ways. Mårdh and Ursing have already described cases of acute pancreatitis following attacks of primary atypical pneumonia due to Mycoplasma pneumoniae, and our investigations are being extended in this direction. The occurrence of abdominal pain and other symptoms which may be referable to the pancreas in cases of Mycoplasma pneumoniae infection (Feizi et al., 1967) may be of relevance, and the lack of respiratory symptoms in our cases of 'mycoplasma positive pancreatitis' (another finding similar to those of Leinikki et al., 1973) is not an insurmountable obstacle to a causal association, as Mycoplasma pneumoniae infection without respiratory symptoms is well recognised (Marmion, 1967). An indirect means of testing the possibility of an association between the two conditions is by the examination of epidemiological data. Leinikki et al. (1973) were of the opinion that such data as they were able to acquire was against the association.

Fourthly, even if it were shown that the serological results presented here are not due to infection with Mycoplasma pneumoniae but due to some cross-reacting antibody evoked by the pancreatitis, an immunological phenomenon which is regularly found in $30 \%$ of cases of this disease must be worthy of further investigation.

In conclusion it would seem that the results of the present study support those reported by Leinikki et al., 1973, in that a substantial proportion of patients with acute pancreatitis have serological evidence of infection with Mycoplasma pneumoniae, but that the explanation of these findings, and in particular the proof or denial of a causal association between the infection and the pancreatitis, must await further investigation. The possibility that such a link might exist is especially interesting in view of the susceptibility of Mycoplasma pneumoniae to several common antibiotics.

We thank those several clinicians in the Leeds General Infirmary who allowed us to study their patients, and Dr M. H. Hambling for advice and encouragement. We are also grateful to Miss B. McLean and Mr G. Chance for their excellent technical assistance, and to Dr C. Patricia Bradstreet of the Standards Laboratory, Central Public Health Laboratory, Colindale Avenue, London, for the provision of complement-fixation antigens. Finally, we are very grateful to Dr. G Bruce-White, Public Health Laboratory, Liverpool, for his kindness in confirming the serological results.

\section{References}

Acosta, J. M., and Ledesma, C. L. (1974). Gallstone migration as a cause of acute pancreatitis. New England Journal of Medicine, 290, 484-487.

Bradstreet, C. M. P., and Taylor, C. E. D. (1962). Technique of complement-fixation test applicable to the diagnosis of virus diseases. Monthly Bulletin of Ministry of Health and the Public Health Laboratory Service, 21, 96-104.

Cruickshank, R., Duguid, J. P., Marmion, B. P., and Swain, R. H. A. (Eds.), (1973). Medical Microbiology, Vol. 1, 12th edn. Churchill Livingstone: Edinburgh.

Edlund, Y. (1970). The etiology and pathogenesis of acute 
pancreatitis. Schweizerische medizinische Wochenschrift, 100, 1174-1178.

Feizi, T., Maclean, H., Sommerville, R. G., and Selwyn, J. G. (1967). Studies on an epidemic of respiratory disease caused by Mycoplasma pneumoniae. British Medical Journal, $1,457-460$.

Hayflick, L. (1967). (Ed.) Biology of the mycoplasma. Annals of the New York Academy of Sciences, 143, 1-824. Kelly, T. R. (1976). Gallstone pancreatitis: pathophysiology. Surgery, 80, 488-492.

Leinikki, P., Pantzar, P., and Tykka, H. (1973). Antibody response in patients with acute pancreatitis to Mycoplasma pneumoniae. Scandinavian Journal of Gastroenterology, $8,631-635$.
Mårdh, P-A., and Ursing, B. (1974). The occurrence of acute pancreatitis in Mycoplasma pneumoniae infection. Scandinavian Journal of Infectious Diseases, 6, 167-171.

Marmion, B. P. (1967). The mycoplasmas: new information on their properties and their pathogenicity for man. In Recent Advances in Medical Microbiology, Edited by A. P. Waterson. Churchill: London.

Thal, A., and Molestina, J. E. (1955). Studies on pancreatitis. III. Fulminating haemorrhagic pancreatic necrosis induced by means of staphylococcal toxin. Archives of Pathology, 60, 212-220.

Ursing, B. (1973). Acute pancreatitis in Coxsackie B infection. British Medical Journal, 3, 524. 